\title{
Sustainable Digital Talent Ecosystem in the New Era: Impacts on Businesses, Governments and Universities
}

\author{
Tugba Karaboga1 $\odot$, Yonca Deniz Gurol2 $\odot$, Ceylan Merve Binici3 $\odot$, Pınar Sarp4 $\odot$
}

\begin{abstract}
Future work will become more digital-oriented and the term digital talent will become the essence of the future workforce. In a digital work design, digital talents, digital fluency, digital networks, and digital platforms will be the most pronounced words. As a result of the rapid digital transformation effort all over the world, the huge increase in the demand for digital skills has led to a worldwide digital talent gap. To close this gap and to expand the digital talent ecosystem in a country, corporations, governments, and higher education institutions should act together. Universities have to understand the digital capability needs of employers to prepare digitally employable graduates for digitally dominated business environments. Governments should attract digital talents to simplify and digitize their services and operations. Corporations should attract digital talents to succeed in digital transformation and gain a competitive advantage. In this study, we emphasized the effect of digital transformation and digital talent shortage on governments, corporations, and universities. Then we highlighted the importance of their collaboration to develop and sustain digitally talented people in a country. We hope this study will be an encouraging guide to enhance partnerships between governments, corporations, and universities to better manage the digital talent shortage.
\end{abstract}

\section{Keywords}

Digital talent management, digital transformation, government role, corporation role, university role

\section{Introduction}

The information age reshaped all societies, economies, cultures and organizations in the $21^{\text {st }}$ century (Castells, 2011). Digital social networks started to create organizational and structural changes in every aspect of our lives and works (van Dijk, 2016). This rapid digitalization gives way to a digitally advanced and connected world (Bell, 2011). The rising amount of information in the technology age has made digital skills vital assets for organizations (van Deursen \& van Dijk, 2011). Especially, advances in big data and AI technologies have changed the nature of jobs and the way of performing work tasks. The concept of talent

1 Corresponding author: Tugba Karaboga (Res. Asst.), Yildiz Technical University, Faculty of Economics and Administrative Sciences \& TUBITAK PhD Scholarship, Istanbul, Turkey. E-mail: hidirlar@yildiz.edu.tr ORCID: 0000-0003-3830-3536

2 Yonca Deniz Gurol (Prof. Dr.), Yildiz Technical University, Faculty of Economics and Administrative Sciences, Istanbul, Turkey. E-mail: gurol@yildiz.edu.tr ORCID: 0000-0002-0618-5750

3 Ceylan Merve Binici (PhD Student), Yıldız Technical University, Faculty of Economics and Administrative Sciences, Istanbul, Turkey. E-mail: ceylan@yildiz.edu.tr ORCID: 0000-0002-7672-5185

4 Pınar Sarp (Res. Asst.), Istanbul Kultur University, Faculty of Economics and Administrative Sciences, Istanbul, Turkey. E-mail: p.sarp@iku. edu.tr ORCID: 0000-0003-3022-5182

To cite this article: Karaboga, T., Gurol, Y. D., Binici, C. M., \& Sarp, P. (2020). Sustainable Digital Talent Ecosystem in the New Era: Impacts on Businesses, Governments and Universities. Istanbul Business Research, 49(2), 360-379. http://doi.org/10.26650/ibr.2020.49.0009 
management has also developed in parallel with the information age and has caused people to become the most valuable capital in creating competitive advantage (Altınöz, 2018).

Digital transformation refers to changes in society and industries as a result of the rising use of digital technologies (Agarwal, Gao, DesRoches, \& Jha, 2010). For companies, it refers to leveraging digital technologies to improve business processes, enhance customer experience, create new business models and increase firm performance (Piccinidni, Hanelt, Gregory, \& Kolbe, 2015). The increasing exploitation of digital technologies such as big data, real-time analytics, artificial intelligence (AI), internet of things, virtual reality and cloud systems also affects talent management systems of organizations. According to Manyika et al. (2017), the developments in big data and AI technologies reduce the importance of traditional jobs and create new job opportunities. Changing workplaces have already created flexible and independent jobs such as freelancers, independent contractors and self-employed individuals especially in the technology-dependent sectors. Most of the independent job workers report higher job satisfaction than traditional job workers because of the higher job flexibility, creativity and variety in the workplace.

Traditional talent management is defined as "strategies and protocols for the systematic attraction, identification, development, and deployment of individuals with high potential who are of particular value to an organization" (Tansley \& Sempik, 2008). The changing expectations of digitally talented employees create challenges for traditional ways of talent management and workplace designs. Talent management is important for achieving an organization's strategic goals (Collings \& Mellahi 2009). In the digital age, while businesses are trying to realize digital transformation of business processes, it will be inevitable for talent management to become digital. In the literature digital talent management has not a common definition. Generally digital talent management can be defined as attracting, motivating and retaining digitally talented workers depending on digital talent markets with various digital platforms or developing existing talents' skills and capabilities according to newly emerging digital skill needs of companies (Kiron et al., 2016).

The concept of digital talent is one of the most important subjects for the future of the work environment. Digital talent has become popular in the management literature with a great focus on digital transformation studies. Although there is not a common definition for the term "digital talent", it is used to refer to digital technology-oriented skills and capabilities for a specific job. A joint survey of Capgemini and Linkedin (2017) indicates that organization-wide digital talent gap has become a big challenge that affects both competitiveness and digital transformation progress negatively. More than half of the companies stated that the talent gap both in hard and soft digital skills damages their business progress. Hard digital skills emerge with the latest technological advances. Cybersecurity, cloud computing, analytics, web development, mobile application design, big data, AI and robotics are highly demanded 
hard digital skills. Soft digital skills are related to people's mindset and ability to understand and direct human beings. Customer-centricity, passion for learning, collaboration, data-driven decision making and comfort with ambiguity are highly demanded soft digital skills. This report also states that digital talents prefer organizations where flexible work-life balance, flat organizational structure, collaborative workplace, career development and training programs, agile culture and digital transformation programs are welcomed.

In this study, digital talent shortage, which is one of the biggest global workforce challenges, is handled from different perspectives. Digital brains are the most valuable assets for a country and technology is not enough to develop it alone. It is only possible by understanding the technological innovations in the most accurate way and taking advantage of know-how and skills at the maximum level through the workforce. It is also argued that digital talent shortage is not only a business concern. Governments, educational institutions and businesses in a country should work together to prepare and implement strategic digital plans on what a country can do to cover the digital talent gap. In the rest of the paper, action plans for governments, educational institutions and corporations are provided depending on literature review, reports of global consulting firms and worldwide examples. Firstly, the impact of digital transformation and digital talent shortage on governments, educational institutions and corporations is discussed. Then, collaborations between state, educational institutions and businesses to fill the digital talent gap in a country are mentioned. Finally, recommendations for these three groups are given to prepare themselves for the coming digital talent war.

\section{The Impact of Digital Transformation on Businesses, Governments and Universities}

It is clear that digital technologies are reshaping jobs, workplaces and workforces in all sectors. Especially most of the administrative, routine and repetitive tasks are realized by automated systems and machines without human interaction. Today, digital transformation is in the agenda of every industry and many global consulting firms. Academicians and researchers are investigating the digital transformation from various perspectives. Depending on various readings from global consulting firms and academic research papers (e.g. Kane et al., 2015; Hess, Matt, Benlian, \& Wiesböck, 2016; Kane et al., 2016; Kiron et al., 2016; Mura, 2018; Das, 2017; Aybek, 2017; Bughin et al., 2017; Hanna, 2018; Cukier, 2019; BHEF, 2019; BCG, 2019 ) the following table is created in which corporations, educational institutions, and governments are investigated to understand how digital transformation is shaping them and what success strategies are needed to reshape them as digital entities (see Table 1). 
Table 1

Success Strategies for Digital Transformation of Corporations, Governments and Universities

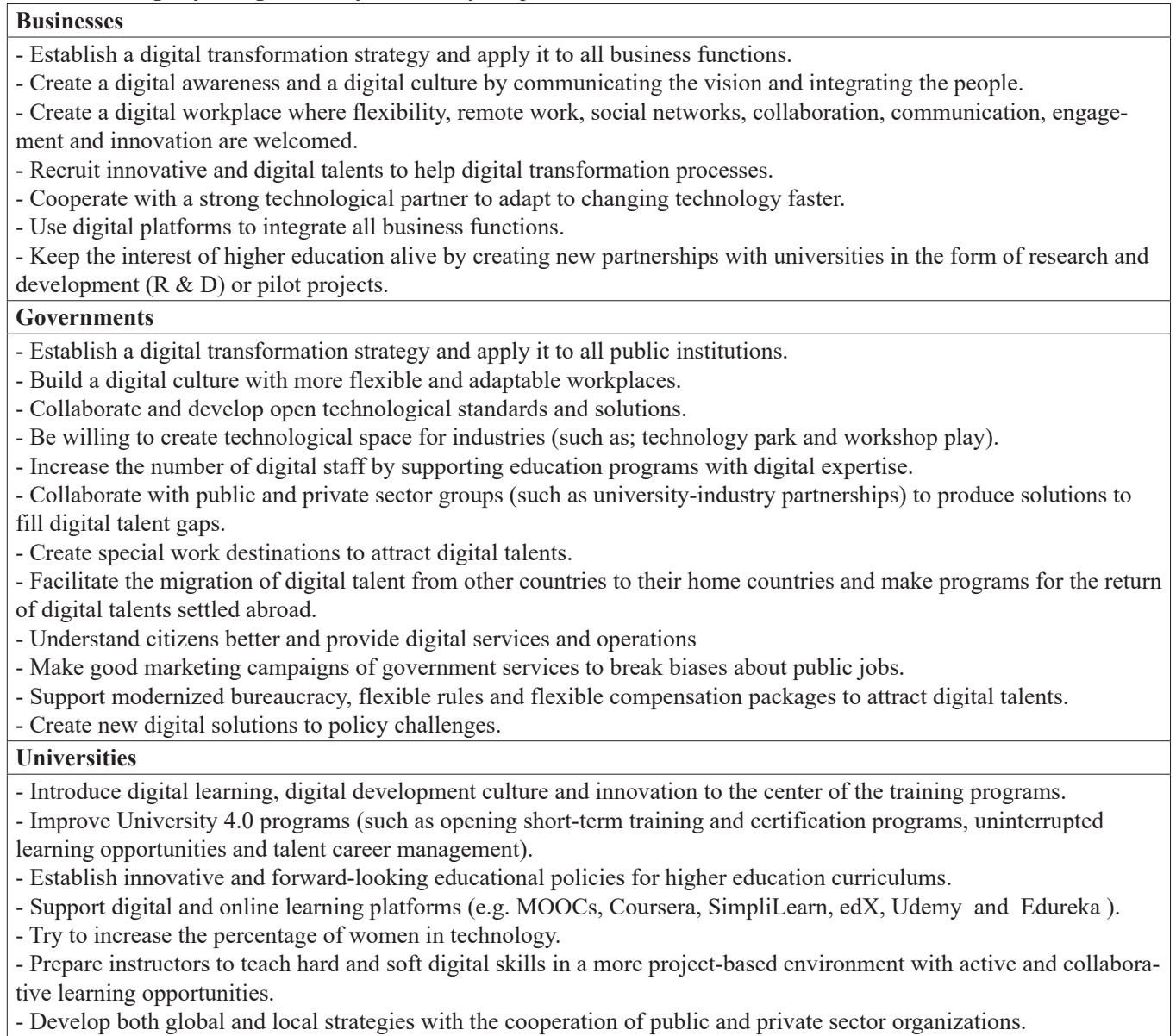

As it is understood from the table above, the latest digital technology developments in big data, automation, AI, IoTs and machine learning do not only affect the business world, but also affect governments and educational institutions. Governments, corporations and higher education institutions need urgent action plans and strategies to respond to the benefits and challenges of digital technologies. These three groups have a great interest in digital transformation and they should act together to achieve digital transformation and to fill the digital talent gap in a country. In the rest of the paper, we will investigate how digital technologies are shaping these three groups and how they can support digital talent development for the future workforce. 


\section{Businesses}

With the development of the digital world, the areas where companies compete become diverse and more challenging. The scarcity of resources and the increase in the severity of competition forces companies to develop employee skills and capabilities. It is necessary to know potential digital talents, in which position they will be evaluated and how they can be developed within the company. Digital talents should not only come from acquiring new staff for specific jobs, but also come from the development of employees in existing roles. Employees who cannot adapt at this point should be eliminated and new talents who have required capabilities and skills should be recruited and more attention should be given to the development of these employees to meet the needs that will arise with the development of the digital world (Strack, Dyrchs, Kotsis, \& Mingardon, 2017).

In 2016, a study by MIT Sloan Management Review and Deloitte found it difficult to retain talented people in existing businesses (Kane et al. 2016). It is seen that approximately 2590 managers emphasize the need for a new and different talent base to survive in the worldwide digital competition. If employers do not provide the opportunity to develop digital skills, it is impossible for companies to retain digitally talented employees. According to this, not only young and less experienced employees, but also middle and high-level managers who have a critical position in a company, can move to digitally advanced companies if they do not have the opportunity to develop themselves in their existing companies (Kane, Palmer, Philips, \& Kiron, 2017; Kane, 2015).

Global research companies have investigated the effect of digitalization on workplaces and workforce. For example; a recent survey of Randstad US (2019) indicates that $40 \%$ of employees left a job "because they didn't have access to the latest digital tools". Employee respondents identified factors that influence their decision to join a company such as the company's use of the latest digital tools $(80 \%)$, an innovative culture (72\%), and the company's reputation as a digital leader (62\%). Also, 2018 Deloitte Global Human Capital Trends Survey indicated that AI, robotics, and automation technologies have increased the importance of technical skills (65\%), complex problem-solving skills (63\%), cognitive abilities (55\%) and process skills (54\%). But again, companies do not have well-established plans to cultivate them.

According to the joint digital business study by MIT Sloan Management Review and Deloitte in 2016, attracting and retaining talent is one of the most serious digital threats and today's talents give importance to digitally mature work environments where they can develop and demonstrate their skills and capacities (Kane et al., 2016). Also, this study highlights two different approaches to attract and retain talent in a digital business environment. One is focusing on digital talent markets based on digital platforms with highly skilled contractors and consultants. Digital talent markets adapt their strategies according to changing tech needs and develop their members' skills and capacities to compete in the market. The second approach 
is developing existing employees' skills and capabilities with continuous training programs and career opportunities. (Kiron et al., 2016).

High performing global companies know a lot about attracting, motivating and retaining digital talents. For example; Facebook supports the fulfillment of digital talents by letting them be part of projects that will have a great impact on the world. Also, Facebook supports continuous learning, taking initiative and work-life integration with authenticity, creativity and transparency. Another example is the partnership between P\&G and Google to develop digital skills of employees. $P \& G$ worked with Google to develop the digital capabilities of employees about how to use and implement digital technologies and platforms. In addition, with the employee exchange program, $P \& G$ and Google's employees in marketing teams took part in one another's strategic meetings and programs to gain expertise about digital marketing (Osborne \& Winston, 2016)

It is important for companies to reach the digital talents they need and to integrate them. The creation of a dynamic environment that can be called a digital talent market or a digital talent pool will provide advantages for both companies and digital talents. Such environments not only bring companies and talents together but also bring enterprises together with other businesses. The common features of these environments are that they enable the digital market to reach the resources that will meet all the technological needs of any organization with its experts in the most demanded positions and with the most demanded skills. Counselors play an intermediary role in these platforms which aim to achieve mutual benefit by accessing talents. They often reach the characteristics, experience and professional knowledge of digital capabilities and present objective criteria, comments and evaluations as reports to the company.

It is difficult to identify the right paths without understanding the digital employees, who are prone to data-driven decision-making, focus on user-oriented product and service development and creativity, and who have a tendency to work collaboratively and are agile in interdisciplinary teams. Given the skills they have and the needs of the market, it is not possible to attract those people who can find jobs quickly and easily with the traditional recruitment practices. It is necessary to reach these people via virtual environments and mobile applications to enable them to display digital skills. TopCoder, Kaggle, Codility, and HireIQ are some examples of digital platforms allow users and candidates to show their technical skills and Good\&Co and HackerRank are examples of digital talent platforms helps companies to match skills requirements of the company with a candidate's skills and capabilities (Bhens, Lau, \& Sarrazin, 2006).

In 2016, GM hired not only the Sidecar software but also 20 employees with digital skills and know-how, including the founding and chief technology officer. It should not be forgotten that it is not enough to discover and attract talents to the company, it is also necessary to create an environment in which they want to stay for a long time. Programs and policies that 
create personal appreciation, create a positive work-life balance, and develop a collaborative, flexible work environment can help ensure that talented employees remain within the company. Work Market Inc., provides internet-based services in the communications industry. The entrepreneur offers a freelance workforce platform and market space. The company serves in a variety of markets by offering a cloud-based contractor management platform to manage the free workforce, including contract selection and recruitment, distribution, ongoing workforce management, related payments, and legal compliance. Topcoder Inc. provides digital talent management support to companies through project managers, providing access to an almost unlimited talent pool that runs $24 / 7$, including on public holidays. With over one million members in the world, Topcoder enables members to learn more about technology and develop practical skills through specialized communities to increase awareness and adoption of technology. Turkey's largest investment company SoftTech offers consulting services to well-established companies in finance, banking, logistics and real estate sectors and it helps them adapt to the digital world based on the mission "customers to digitize" (Osbome \& Winston, 2016).

\section{HR's Role in Filling Digital Talent Gap}

Digital technologies are giving way to the emergence of new jobs which require high digital skills and capabilities. However, digital transformation of businesses is faster than digital capability building. Therefore there is a big talent shortage all around the world. BCG expects a severe digital talent shortfall around the world by 2020 and a Gartner study states that $30 \%$ of tech jobs will be unfilled due to digital talent shortfalls (BCG; 2017). Closing the digital talent gap of the companies falls to HR professionals who have profound implications for business functions, should not be underestimated in the adoption of new approaches. HR people can respond to this challenge in two ways (BCG; 2017, 2019). One is attracting outside digital talents by meeting their distinctive demands such as flexibility, mobility, virtual work, connectedness through digital platforms, reduced autonomy and personalized offerings. The other is training and developing potential talents in achieving new digital capabilities and skills around big data, AI, automation, software development, programming, and cybersecurity.

In order to turn organization-wide digital transformation investments into business success, HR people need to improve digital skills and capabilities of their workforce at all levels. Hard digital skills (such as programming, data analytics, machine learning, AI, automation and robotics) depends on technical know-how and soft digital skills (such as learning ability, customer-centricity, collaboration, flexibility, adaptability and comfort with ambiguity) are more human-specific skills and are the most valuable in the digital transformation of organizations because in a transformation and change period, digital talents can lead employee groups by relaxing them about their fears and doubts (Capgemini \& Linkedin, 2017; Cukier, 2019). 
For business success during the digital transformation process, HR leaders should close the digital talent gap in a company. The role of HR in digital talent management is to promote communication and cooperation beyond creating an environment that supports innovation. In a mixed workforce environment (e.g. full-time employees, freelancers and remote workers) maintaining balance and supporting productivity is possible through HR practices where coordination and management skills are at the forefront. Therefore, the challenges facing HR professionals today are not limited to the ability of gaining and managing digital talents. HR is also responsible for taking care of basic needs such as work and life balance, career perspectives, satisfaction and mobility (Mura, 2018). Recommendations to fill digital talent gap are as follows (Mura, 2018; Das, 2017; Dhanabhakyam \& Kokilambal, 2014; Ratten, 2014):

- HR should prepare a well-established digital strategy to attract, develop and retain digital talents. Also, this digital strategy should be the priority of every department as part of their strategic planning for gaining a competitive advantage in the market.

- HR should develop training programs for not only technical skills but also adapting and developing new ways of working in alignment with the organization-wide digital strategy. HR training programs should help employees to adapt and develop new ways of working aligned with newly developed technologies.

- HR should support digital transformation in the organization with a digital culture where employees can continuously learn and upgrade their digital skills.

- HR people should create digital workplaces where digital talents feel flexible while trying on innovative solutions. Social networks to create real-time communication among new talents, peers and mentoring groups are valuable for the retention of talents.

- HR people should find various ways of acquiring digital talents. One is focusing on digital talent markets based on digital platforms with highly skilled contractors and consultants. Mobile-friendly job boards, company career sites, blogs, social media sites and community forums are among the sources organizations are relying on to identify and attract talent. The second approach is developing existing employees' skills and capabilities with continuous training programs and career opportunities.

- HR should analyze employee data regularly to understand training needs as a part of data-enabled talent processes. Data-driven talent management practices are crucial for every step of the employee lifecycle by creating effective hiring, training and coaching. It also helps HR people to identify talent problems early in the process and intervene.

- HR should be able to manage digital talents' career paths and work-life balance with competitive compensation packages. In this way, they can perform their role more efficiently. 


\section{Governments}

For governments, there is an urgent need to transform their public services into digital-based applications. However, while private sector organizations have transformed over the past two decades, public sector organizations have still been managed by the early policies such as hard hierarchical ranks, rigid job classifications, high discipline, and centralized structures. This challenge prevents public sector institutions from attracting a talented workforce.

Governments should have the ability to rapidly adapt to changes in their environments and should create systems to understand the latest trend and developments in a country to encourage the adoption of new skills, capabilities and policies (Mergel, Gong, \& Bertot, 2018). Attracting digital talent to a country actually contributes greatly to economic success and digital development. The main role of governments should be creating attractive work destinations for digital talents (Hanna, 2018). Otherwise, they can leave their workplaces for better opportunities in other countries and encourage local digital talents to reside in other countries (BCG, 2019).

Countries with high levels of socioeconomic status have access to information and communication technologies, also the speed of obtaining information and the potential for obtaining accurate information is high. Socioeconomic levels of societies reveal the digital gap or digital division. The digital divide, which we can call the levels of access to information and communication technologies of the societies, is one of the factors that affect the speed and prevalence of both countries and individuals. The large differences between the digital gap and the socio-economic situation of the countries play a decisive role in the process of accessing information (Değirmen, Vural \& Özbükerci, 2016). This situation affects the digital talent management need of a country.

In order to avoid a digital talent shortage, governments can make strategic workforce plans considering the demand and supply of digital workers. Governments can increase the number of digital staff by supporting education programs with digital expertise (BCG, 2019). They should analyze the skills that enterprises need to determine which new courses are required and compare the results in academic training programs. In this incomplete context, new programs should be added to meet changing skill requirements in areas such as project management and technology-intensive jobs. Practical knowledge and soft skills training must pass through practical learning and the government should encourage universities to teach new topics in digital technologies.

Governments not only support the development of digital talents in a country but also compete with the private sector to attract and retain digital talents to the government body. Today, digital transformation is in the agenda of many governments but they suffer from a shortage of digital professionals which are also highly in demand in private sector corporations. Bureaucracy, rigid rules and policies, lack of flexibility, and non-negotiable compensation are some exam- 
ples of issues that limit governments' ability to attract digital talents (Aitken, 2018). The digital transformation of governments is a challenging job. There is a need for digital policies, digital strategies, digital culture and change management with the support of digital professionals in the government staff. Cukier (2019) recommended a digital strategy for the digital transformation of the Canadian public service to create a digitally talented workforce. These recommendations included: building a digitally ready public service to attract world-class digital talents; building a digital culture with more flexible and adaptable workplaces; developing accountability mechanisms with measurable targets; modernizing practices in every stage of HR; training not only hard digital skills but also soft skills including critical thinking, communication, collaboration and decision making; applying gender and diversity lenses through the value chain; supporting public and private partnership to reach talents and new approaches; making good marketing campaigns of government services to break biases about government jobs.

Digital transformation investment in public institutions is more vital than ever before and these recommendations are crucial to overcome digital talent shortfall across every area of government. Competitive digital government strategies can make public sector corporations desirable places to work for digital talents (Hanna, 2018). A digital culture, flexible workplaces, competitive compensation packages, simplified and digitized public services, modernized bureaucracy, training on emerging digital trends, career progression opportunities and high level of transparency, accountability and citizen participation are attractive for digital talents. Therefore, governments should be engaged with their countries' digital ecosystem to compete with the private sector and to attract digital talents in a country.

\section{Universities}

Educational institutions at all levels are important for strengthening the economic development and global reputation of a country. Countries that have succeeded in transforming their educational systems according to the changing needs of the digital era can provide a digital workforce for both private and public sector organizations. Digital talent shortage all around the world makes transformation necessary in educational institutions, especially in higher education systems (Cardenas-Navia \& Fitzgerald, 2019). During the transformation process, collaboration among government, business and educational institutions is required to plan changing skills and needs of the upcoming workforce and take action accordingly because most of the specialties gained today through university education will be largely automated in the coming few years. Therefore, adapting higher education programs according to the changing needs of industries, governments and society is crucial for filling the skill gaps and accelerating digital transformation in a country (Bughin et al., 2017).

Rapid digitization brings also uncertainty and complexity. In such a digital environment, the digital capability needs of companies change very fast. To support industries' digital 
skill gap, higher education institutions need to introduce digital learning, digital development culture and innovation to the center of the training programs. In the digital age, universities are expected to have a structure that can manage this age by developing both global and local strategies with the cooperation of public and private sector organizations (Aybek, 2017).

According to the results of the 2016/2017 Talent Gap Survey conducted by Manpower Group; Japan (86\%), Taiwan (74\%) and Hong Kong (73\%) are among those in the top ranks of high-tech manufacturing countries where the digital talents are most frequently employed. According to this report, a talent crisis emerges as a result of two important causes: lack of experience and technical insufficiency. The report emphasizes that the education system alone cannot develop the competencies required by the Digital Age in the 21st century. Universities become inadequate to close this gap if the state-private sector-university triangle cannot demonstrate effective cooperation.

What should be considered by universities is how to manage tools and approaches for learning digital skills, how to make these processes more effective, how to sustain lifelong learning, and how to become digitally manageable individuals(Cardenas-Navia \& Fitzgerald, 2019). In this context, guidance and measurement assessment strategies should be followed, which can effectively monitor, learn and guide the learners throughout the process by employing digital technologies effectively (Aybek, 2017). Higher educational institutions can provide a digital talent development environment by using new applications such as University 4.0. providing uninterrupted learning opportunities over traditional, blended or multiple different channels; opening short-term training and certification programs to gain various professional digital competencies; supporting programs between industry, researchers and students, increasing scientific researches towards transforming information into reality, providing support for the opening of companies producing advanced technology within the university, establishing communication networks and providing coordination between different subjects (Aybek, 2017).

In curriculum design, innovative and forward-looking educational policies are important for higher education institutions. It is the task of the universities to keep up with digital change, to manage digital change, and to train digital talents that meet the competencies required by the digital age. At this point, STEM (Science, Technology, Engineering and Mathematics) training is noteworthy. The STEM system provides improvements in curricula, educational methods and teacher education to raise individuals who have creative, innovative, analytical, critical thinking and problem-solving skills. Besides, the content of higher education ensures the enrichment of the work environment by meeting the needs and expectations of the business world and by enhancing the cooperation between the university and the industry (Akgündüz et al., 2015).

Digital talent acquisition and internal up-skilling of existing talents require partnerships with higher education institutions. The Business-Higher Education Forum (BHEF) is an or- 
ganization comprised of Fortune $500 \mathrm{C}$-level executives and leading university presidents dedicated to creating innovative education solutions and highly skilled future workforce to increase America's competitiveness. A research from the Business-Higher Education Forum and Burning Glass Technologies (2018) categorizes foundational skills of the digital economy in three groups: human skills, digital building blocks and business enablers. Human skills are related to critical thinking, creativity, communication, analytical skills, collaboration, and relationship building. Digital building blocks skills are critical for many digitally intense jobs and include managing data, analyzing data, software development, computer programming, digital security and privacy. Business enablers' skills have a synthesizing and integrative role in the workplace. Project management, business process, communicating data, and digital design are business enablers' skills which turn theoretical knowledge and skills into practice. According to this study, a "blended digital professional" is someone who combines these three foundational digital skill areas with domain knowledge that is specific to a company, organization, or workforce.

These skill areas are important for academic and higher education programs to prepare digitally skilled new graduates for digitally dominated business environments. Digital skills are not only applicable to tech and STEM majors but also available for all students in all disciplines (Cardenas-Navia \& Fitzgerald, 2019). BHEF members from diverse backgrounds work together to create an impactful higher education curriculum and to prepare highly skilled employable graduates to meet changing business demands. Here are some partnerships under BHEF. The City University of New York and IBM partnership supports students in data science and analytics and urban sustainability. The Northeastern University, Raytheon, IBM, and Others partnership integrates work and learning in the industry informed IT and cybersecurity. The Washington University in St. Louis and Boeing partnership provides alternative engineering models for nontraditional students (BHEF, 2019). Depending on strategic business and higher education partnerships, BHEF (2019) has made some recommendations for other businesses and higher education institutions.

- Business-higher education partnerships to support regional talent ecosystems are important to create diverse and sustainable platforms for building successful new career pathways and job-training programs.

- Engaging C-level business and academic leaders is critical for guiding corporate and academic policy with shared goals. Their engagement can encourage others to build STEM and digital-skills pathways for the future development of the workforce.

- Developing a common language among partners is crucial to translate, clarify, and align expectations, responsibilities, and outcomes.

- Supporting and integrating work-based learning programs with talent and recruitment 
strategies is important to become well prepared for $21^{\text {st }}$ century digital intensive jobs.

- University partnerships help companies to expand their digital talent strategies.

- Reviewing HR strategies and human-capital planning is vital to signal and recruit diverse STEM and digitally skilled talents.

\section{The Partnerships between Businesses, Governments and Universities}

Digital technologies continue to expand rapidly. Smart machines, robots, digital platforms and intelligent assistants take place in the business environment and as a result, many digital job opportunities have emerged. However, there is not enough digital talent to fill every digital role. Therefore, all countries and all industries are facing this challenge and trying to find new innovative ways to attract and retain digital talent. Collaborations among governments, higher education institutions and businesses can prevent this digital talent crisis by finding ways of developing complementary digital skills for the workforce of the future rather than competing with technology (Bughin et al., 2017). These collaborations are also important to share the resources, risks, and mutual benefits in their pursuit of a common set of goals. Businesses have resources and social impacts (being an example for other ones) that may aid in the development and spread of strategies to close the gap; on the other hand governments have power and influence to alleviate uncertainty and capitalize on the strategic opportunities related to improvements and universities have education opportunities to discover and guide talents early.

The World Economic Forum 2018 report predicts that nearly 75 million jobs will be eliminated as a result of AI technologies by 2025, but it is also expected that nearly 133 million new jobs will be created. At the same time, 54 percent of employees are expected to reskill with digital skills and capabilities to take advantage of these new job opportunities. Therefore, workforce development with digital expertise and gaining and retaining digitally talented employees are the hottest topics of business and HR leaders of today's companies.

Most of the companies are aware that new technologies develop quickly and companies cannot keep up this speed with their long term workforce developments and training plans. In this environment, lifelong and continuous learning become vital both for companies and employees. At the same time, technological advances affect traditional business structures and processes, the way of doing work, value chains of companies and traditional job roles. On the other hand, disruptions in the economy, politics, social life and educational systems have risen dramatically. In this digital transformation environment governments, businesses and higher educational institutions are needed to work together to deepen the regional digital talent pool and develop digital workforce skills needed by today's organizations. 
IBM Global Skills Survey in cooperation with Oxford Economics is applied to more than 5,600 global executives from 18 industries and 48 countries to understand the future skills challenges and the future needs to overcome these challenges (King et al., 2016). In this survey, industry leaders are asked to rank institutions according to the responsibility for developing and maintaining workforce skills and capabilities. Respondents believe that governments (78\%), higher educational institutions (67\%) and private sector (49\%) are responsible for developing and maintaining worker skills respectively. But it is not possible for the government, universities and the private sector to succeed on their own. They all have their own strengths and weaknesses. If they act together, they can combine their strengths and move faster by reducing the negative effects of their weaknesses. For example; governments may face higher geopolitical, demographic, economic and social constraints when they act alone. However, if the state assembles higher education and private sector industries around a digital talent development vision, it will accelerate the formation of the digital talent ecosystem by sharing responsibility. Incentives for the private sector and higher education investments for digital skills development programs can be provided by governments. Educational institutions and the private sector can act together to create work-based and practice-based learning programs. Governments can encourage educational institutions and the private sector to update their curriculums and training programs according to technological changes. Industry leaders can work with public and higher education institutions to expand internship and certification programs (King et al., 2016).

The systematic relationship among universities, businesses and governments enables learning and assimilating new technologies, transforming them into production and development ability and adapting this ability to business life, in short, the ability to turn knowledge into information and economic knowledge. At this point, universities manage the process of conducting the necessary research for the production of knowledge and the training of young talents in this field. Businesses enable these talents to turn into a tangible output. The government takes the necessary measures to provide systematic integrity and provides support to institutions. Table 2 is created in the light of various readings from global consulting firms and academic research papers (e.g. Kane et al., 2015; Shmelkova, 2016; Kane et al., 2016; Kiron et al., 2016; King et al. 2016; Mura, 2018; Das, 2017; Aybek, 2017; Bughin et al., 2017; Hanna, 2018; WEF, 2018; BHEF, 2019; BCG, 2019) and summarizes the partnerships among businesses, governments and universities to fill the digital talent gap in a country. 
Table 2

The Partnerships between Corporations, Governments and Universities

\begin{tabular}{|c|}
\hline University - Business Partnership \\
\hline $\begin{array}{l}\text { - Supports regional talent ecosystems. } \\
\text { - Provides work-based learning experiences (such as apprenticeships, internships, co-operative education) to bridge } \\
\text { academic and career success. } \\
\text { - Helps students plan their career and discover themselves during their university education. } \\
\text { - Creates innovative and forward-looking curriculums for universities. } \\
\text { - Facilitates understanding digital skills and capability needs of the private sector. } \\
\text { - Prepares digitally skilled new graduates for digital work environments. } \\
\text { - Uncovers new digital job opportunities in businesses. } \\
\text { - Creates first-mover advantage as a result of a faster response to developing and changing digital technologies. } \\
\text { - Expands digital talent strategies of companies with talent-based training. }\end{array}$ \\
\hline University - Government Partnership \\
\hline $\begin{array}{l}\text { - Builds a learning society with a digital talent ecosystem. } \\
\text { - Develop a digital staff for governments by supporting higher education programs. } \\
\text { - Creates technological spaces to attract digital talents. } \\
\text { - Supports digital development plans of countries by digitally employable graduates of universities } \\
\text { - Provides equal opportunities to train women who are underrepresented in the digital talent population. } \\
\text { - Helps to adapt latest technological innovations by the help of university researchers to catch up with the era and to } \\
\text { even go beyond it. }\end{array}$ \\
\hline Government - Business Partnership \\
\hline $\begin{array}{l}\text { - Accelerates digital transformation in a country by supporting a dynamic digital ecosystem with network systems, } \\
\text { digital platforms and digital talents. } \\
\text { - Provides employment opportunities to prevent the brain drain of talented young people. } \\
\text { - Creates attractive work destinations for digital talents. } \\
\text { - Organizes joint programs to attract digital natives from abroad to their own country and national companies. } \\
\text { - Accelerates digital transformation of governments with temporary employment from technology partners. }\end{array}$ \\
\hline
\end{tabular}

Governments should have some responsibilities to reinvent a country's educational infrastructure to fill the digital skill gap in a country. The basic priority that should be placed into the education system should be to encourage people to learn continuously. By this way, people can learn by updating their knowledge and skills according to changing technological developments. This is a great success factor in the digital world (Shmelkova, 2016). Second, instructors must be prepared to teach hard and soft digital skills in a more project-based environment with active and collaborative learning opportunities. Third, governments should adopt the latest technological innovations to catch up with the era and to even go beyond it. Fourth, governments should support the expansion of digital and online learning platforms with digital education plans. For example; massive open online courses - MOOCs provide interactive learning tools (such as games and forums) to learn new skills and develop career pathways. Finally, government education policies can provide equal opportunities to all members of society without gender discrimination and special attention should be given to education programs to train women who are underrepresented in the digital talent population. 
Jointly, governments should be willing to create technological space for industries. As known, the technology parks and workshops play an important role in helping students to solve work-related problems in technology (BCG, 2017). Also, the collaboration between public and private sector groups (such as university-industry partnerships) can produce solutions to fill digital talent gaps. Governments can create special work destinations to attract digital talents. At the same time, governments should facilitate the migration of digital talent from other countries to their home countries and make programs for the return of digital talent settled abroad (BCG, 2019).

Industries should keep the interest of higher education alive by creating new partnerships with universities in the form of research and development (R \& D) or pilot projects. Strong alliances and partnerships with universities are crucial for all companies and industries. As the industry is digitized, the need for new skills will increase. The industry should cooperate with universities, vocational schools and vocational training providers to create an appropriate curriculum for current and future employees. First of all, businesses need to determine which digital skills are needed. Then, to estimate how many people have these skills and they should determine their talent gaps and make effective training planning. Industries and businesses can provide feedback to universities and academicians about urgent digital capabilities needed to plan future curriculums of universities.

\section{Conclusion and Future Directions}

In a digital work design, digital talents, digital fluency, digital networks and digital platforms will be the most pronounced words. As a result of the rapid digital transformation effort all over the world, the huge increase in the demand for digital talent has led to a worldwide digital talent gap. In this study, it is argued that digital talent shortage is not only a business concern. Digital brains are the most valuable assets for a country. Technology alone is not enough to develop a country. It is only possible by understanding the technological innovations in the most accurate way and benefiting from them at the maximum level through the workforce with that know-how and skills. For this reason, governments, higher education institutions, and businesses in a country should work together to prepare and implement strategic digital plans on what a country can do to cover the digital talent gap.

Digital technologies reduce the share of humans in job tasks while increasing the share of machines. There are many factors affecting this situation. As known, supply chains and multinational companies are important in shaping the structure of the global economy. Skilled local talents are considered important in the selection of businesses' locations. In particular, the cost of pure labor in developing economies is an important one. For instance, in the United Kingdom - skilled local talent availability remains the single most important element for job location decisions and additional relevant factors, such as the flexibility of local labor laws, 
agglomeration effects in the sector or the proximity of raw materials were considered less important than those related to the availability of skilled local talents and labor costs (WEF, 2018). Therefore, partnerships among universities, businesses and governments are important to support the dynamic digital ecosystem in a country with network systems, digital platforms and digital talents.

Digital talent management in the new age is one of the basic responsibilities of companies. To turn organization-wide digital transformation investments into business success, companies need to improve digital skills and capabilities of their workforce at all levels. The world's largest report on digital talents by BCG (2019) states that digitally talented people are more willing to move to other companies and even to other countries in order to gain work experience and develop their career. According to this report, the US, Germany, Canada, Australia and the UK are the five most attractive destinations for digital talents all around the world and digital experts value good work-life balance, learning and training opportunities, career development, a good relationship with colleagues and financial compensation respectively. Therefore, companies and governments should make strategic plans to attract digital talents and to retain where they are.

Digital talent development for universities is crucial for preparing new digitally skilled graduates for digitally dominated business environments and to strengthen the economic development and global reputation of a country (Aybek, 2017). For government institutions, digital transformation investments and digital talent development are more vital than ever before because citizens demand simplified and digitized public services, modernized bureaucracy, a high level of transparency, accountability and participation in public operations (Mergel, Gong, \& Bertot, 2018; BCG, 2019). Therefore, public institutions need to be engaged with their countries' digital ecosystem to compete with the private sector and to attract digital talents to a country.

In this paper, we highlighted the importance of collaboration among governments, businesses, and higher educational institutions to create a digital talent ecosystem in a country to cope with the global digital talent gap. Partnerships between these three groups provide opportunities to assist students, researchers, managers, entrepreneurs, and policymakers for sustainable talent development by giving a chance for the discovery, support, and upbringing of potential digital talents in a country. The common objective of their collaboration is to develop a strong bond among the partners for knowledge, technology and organizational transfer to support digital skills development. We hope that this study will be a guide for the governments, private sector industries and higher education institutions on how to cope with the digital talent gap. 
Peer-review: Externally peer-reviewed.

Conflict of Interest: The authors have no conflict of interest to declare.

Grant Support: The authors declared that this study has received no financial support.

\section{References}

Agarwal, R., Gao, G., DesRoches, C., \& Jha, A. K. (2010). Research commentary-The digital transformation of healthcare: Current status and the road ahead. Information Systems Research, 21(4), 796-809.

Aitken, K. (2018). Governance in the Digital Age. Available at: https://www.ppforum.ca/wp-content/uploads/2018/09/GovernanceInTheDigitalAge-PPF-SEPT2018-EN.pdf (accessed 21.08.2019)

Akgündüz, D., Aydeniz, M., Çakmakçı, G., Çavaş, B., Çorlu, M. S., Öner, T., \& Özdemir, S. (2015). STEM Eğitimi Türkiye Raporu. İstanbul: Scala Basım.

Altınöz, M. (2018). Yetenek yönetiminin algılanması üzerine karşılaştırmalı bir araştırma. Selçuk Üniversitesi Sosyal Bilimler Enstitüsü Dergisi, (39), 82-95.

AYBEK, H. S. Y. (2017). Üniversite 4.0'a geçiş süreci: kavramsal bir yaklaşım. Açıköğretim Uygulamaları ve Araştırmaları Dergisi, 3(2), 164-176.

BCG (2017). Year 2035: Talent War in the Digital Age. Available at: http://image-src.bcg.com/Images/ BCG_Year-2035_Talent-War-Digital-Age_ENG_Jan2017_tcm21-153967.pdf (accessed 21.08.2019)

BCG (2019). Decoding Digital Talent. Available at: https://www.bcg.com/publications/2019/decoding-digital-talent.aspx (21.08.2019)

Bhens, S., Lau, L., Sarrazin, L. (2016). The New Tech Talent You Need To Succeed In Digital. Available at: https:/www.mckinsey.com/business-functions/digital-mckinsey/our-insights/the-new-tech-talent-youneed-to-succeed-in-digital (accessed 28.08.2019)

Bort, J. (2014). Bill Gates: People don't realise how many jobs will soon be lost to computers. Available at: http://www.thejournal.ie/bill-gates-software-automatic-jobs-loss-bots-1363435-Mar2014/ (accessed 28.08.2019)

Brougham, D., \& Haar, J. (2018). Smart Technology, Artificial Intelligence, Robotics, and Algorithms (STARA): Employees' perceptions of our future workplace. Journal of Management \& Organization, 24(2), 239-257.

Brynjolfsson, E. and McAfee, A. (2011). Race against the machine: How the digital revolution is accelerating innovation, driving productivity, and irreversibly transforming employment and the economy. Digital Frontier Press Lexington, MA.

Bughin, J., Hazan, E., Ramaswamy, S., Chui, M., Allas, T., Dahlström, P., ... \& Trench, M. (2017). Artificial intelligence: The next digital frontier. McKinsey Global Institute, 1-80.

Business-Higher Education Forum (2019). Creating Purposeful Partnerships, Available at: https://www. bhef.com/sites/default/files/BHEF_2018_CEO_playbook_0.pdf (accessed 10.11.2019)

Business-Higher Education Forum and Burning Glass Technologies (2018) The New Foundational Skills of the Digital Economy. Available at: https://www.burning-glass.com/wp-content/uploads/New_Foundational_Skills.pdf (accessed 12.11.2019).

Capgemini Research Institute and LinkedIn (2017). The Digital Talent Gap: Are Companies Doing Enough? Available at https://www.capgemini.com/wp-content/uploads/2017/10/Digital-Talent-Gap-Report_Digital.pdf (accessed 28.08.2019) 
Cardenas-Navia, I., \& Fitzgerald, B. K. (2019). The digital dilemma: Winning and losing strategies in the digital talent race. Industry and Higher Education, 33(3), 214-217.

Castells, M. (2011). The rise of the network society (Vol. 12). John wiley \& sons.

Collings, D. G., \& Mellahi, K. (2009). Strategic talent management: A review and research agenda. Human resource management review, 19(4), 304-313.

Cukier, W. (2019). Developing Canada's Digital-Ready Public Service: Attracting and Retaining a Highly Skilled, Diverse Workforce to Support the Government of Canada's Digital Strategy. Public Policy Forum.

Das, G. (2017). Changing Role of People Management in Digital Era. Journal of Industrial Relationship, Corporate Governance \& Management Explorer (e ISSN 2456-9461), 1(3), 22-29.

Değirmen, G. C., Vural, Z. B. A., \& Özbükerci, İ. Bilgi Toplumu ve Dijital Uçurum. INIF E-Dergi, 1(2), $102-118$.

Deloitte (2018). AI, Robotics and Automation. The Rise of the Social Enterprise: 2018 Deloitte Human Capital Trends. Available at: https://www2.deloitte.com/content/dam/Deloitte/at/Documents/human-capital/ at-2018-deloitte-human-capital-trends.pdf (accessed 28.08.2019)

Dhanabhakyam, M., \& Kokilambal, K. (2014). A study on existing talent management practice and its benefits across industries. International Journal of Research in Business Management, 2(7), 23-36.

Hanna, N. (2018). A role for the state in the digital age. Journal of Innovation and Entrepreneurship, 7(1), 5.

Hess, T., Matt, C., Benlian, A., \& Wiesböck, F. (2016). Options for formulating a digital transformation strategy. MIS Quarterly Executive, 15(2).

Kane G. C., Palmer D., Phillips A. N., Kiron D. and Buckley N., "Aligning the Organization for its Digital Future" MIT Sloan Management Review and Deloitte University Press, July 2016. Available at: https:// www2.deloitte.com/content/dam/Deloitte/ie/Documents/Consulting/2016_MIT_Deloitte-Aligning-Digital-Future.pdf (accessed 28.08.2019)

Kane, G. (2015). The Talent Imperative in Digital Business. MIT Sloan Management Review. Available at: https://sloanreview.mit.edu/article/the-talent-imperative-in-digital-business/ (accessed 28.08.2019)

Kane, G., Palmer D., Philips A. N., Kiron D. (2017). Winning the Digital War for Talent. MIT Sloan Management Review. Available at:.https://sloanreview.mit.edu/article/winning-the-digital-war-for-talent/ (accessed 28.08.2019)

King, M., Marshall, A., \& Zaharchuk, D. (2016). Facing the Storm: Navigating the Global Skills Crisis. IBM Institute for Business Value. December.

Kiron, D., Kane, G. C., Palmer, D., Phillips, A. N., \& Buckley, N. (2016). Aligning the organization for its digital future. MIT Sloan Management Review, 58(1).

Lynch, C. (2015). Stephen Hawking on the Future of Capitalism and Inequality. Available at: https://www. counterpunch.org/2015/10/15/stephen-hawkings-on-the-tuture-of-capitalism-and-inequality/ (accessed 28.08.2019)

Man Power Group 2016/2017 Solving The Talent Shotage Report. Available at: https:/go.manpowergroup. com/talent-shortage-2018\#thereport (accessed 28.08.2019)

Manyika, J., Chui, M., Bughin, J., Dobbs, R., Bisson, P., \& Marrs, A. (2013). Disruptive technologies: Advances that will transform life, business, and the global economy (Vol. 180). San Francisco, CA: McKinsey Global Institute. 
Manyika, J., Lund, S., Chui, M., Bughin, J., Woetzel, J., Batra, P., ... \& Sanghvi, S. (2017). Jobs lost, jobs gained: Workforce transitions in a time of automation. McKinsey Global Institute.

McVal Osborne and Sally Winston (2016). Talent Trends: Winning the War for Digital Talent. Available at https://www.polyu.edu.hk/iaee/files/Talent_Trends_Digital-Talent_FINAL.pdf (accessed 28.08.2019)

Mergel, I., Gong, Y., \& Bertot, J. (2018). Agile government: Systematic literature review and future research.

Montealegre, R., \& Cascio, W. F. (2017). Technology-driven changes in work and employment. Communications of the ACM, 60(12), 60-67.

Mura, A. (2018). HR and Talent Management in the Digital Era: Strategy and Challenges. Available at.https:// blog.userlane.com/hr-and-talent-management-challenges-in-the-digital-era/ (accessed 28.08.2019).

Piccinini, E., Hanelt, A., Gregory, R., \& Kolbe, L. (2015). Transforming industrial business: the impact of digital transformation on automotive organizations.

Randstad US (March, 2019). Workplace 2025: The Post-Digital Frontier, Available at https://www.prnewswire.com/news-releases/a-companys-reputation-as-a-digital-leader-greatly-impacts-their-ability-toattract-and-retain-talent-randstad-us-study-finds-300619937.html (accessed 28.08.2019)

Ratten, V. (2014). Indian and US consumer purchase intentions of cloud computing services. Journal of Indian Business Research, 6(2), 170-188.

Shmelkova, L. V. (2016). Personnel for the digital economy: a look into the future. Additional Vocational Education in the Country and in the World, 8(30), 1-4.

Strack, R., Dyrchs, S., Kotsis, A. \& Mingardon, S.(2017). How to Gain and Develop Digital Talent and Skills. Boston Consulting Group. Available at http://image-src.bcg.com/Images/BCG-How-to-Gain-andDevelop-Digital-Talent-and-Skills-July-2017_tcm9-165367.pdf (accessed 28.08.2019).

Tansley, C., \& Sempik, A. (2008). Talent management: Design, implementation and evaluation.

Van Deursen, A., \& Van Dijk, J. (2011). Internet skills and the digital divide. New media \& society, 13(6), 893-911.

Van Dijk, J. (2016). A

WEF (World Economic Forum). (2018). The future of jobs report 2018. World Economic Forum, Geneva, Switzerland. Available at http://www3.weforum.org/docs/WEF_Future_of_Jobs_2018.pdf (accessed 28.08.2019) 